\title{
Newborn with tetralogy of Fallot and absent pulmonary valve
}

\author{
Paul Chen • Maria Ladino-Torres
}

Received: 24 September 2010 / Accepted: 29 September 2010 /Published online: 2 November 2010

(C) Springer-Verlag 2010

A term newborn girl with prenatal diagnosis of tetralogy of Fallot with absent pulmonary valve syndrome (TOF-APV) and massively dilated main and proximal right pulmonary arteries presented with tachypnea and cyanosis. Chest radiograph demonstrates hyperinflated right lung and a large $2.7-\mathrm{cm}$ dilated right pulmonary artery (Fig. 1, arrows). Postnatal echocardiogram also demonstrated discontinuous left pulmonary artery. Contrast-enhanced CT of the chest reveals massively dilated right pulmonary artery $\left({ }^{*}\right)$ with mass effect upon the right main stem bronchus (short arrow) (Fig. 2). Right upper lobe atelectasis is also present (Fig. 2, large arrow).

TOF-APV is a rare variant of TOF and comprises only $3-6 \%$ of all infants with TOF. Patients have massive

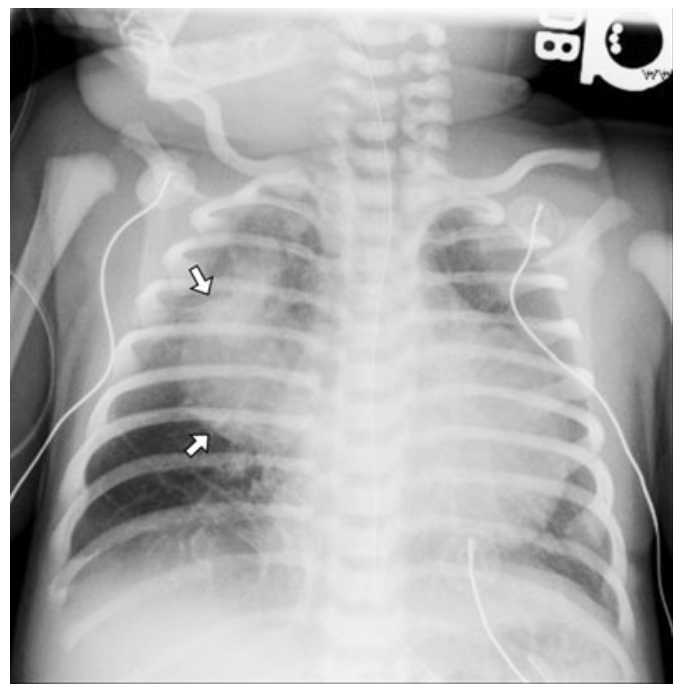

Fig. 1 Supine chest radiograph

P. Chen $\cdot$ M. Ladino-Torres $(\bowtie)$

Department of Radiology, Section of Pediatric Radiology,

University of Michigan Health System,

1500 E. Medical Center Drive, Rm. F3345,

Ann Arbor, MI 48109-5252, USA

e-mail: marialad@med.umich.edu

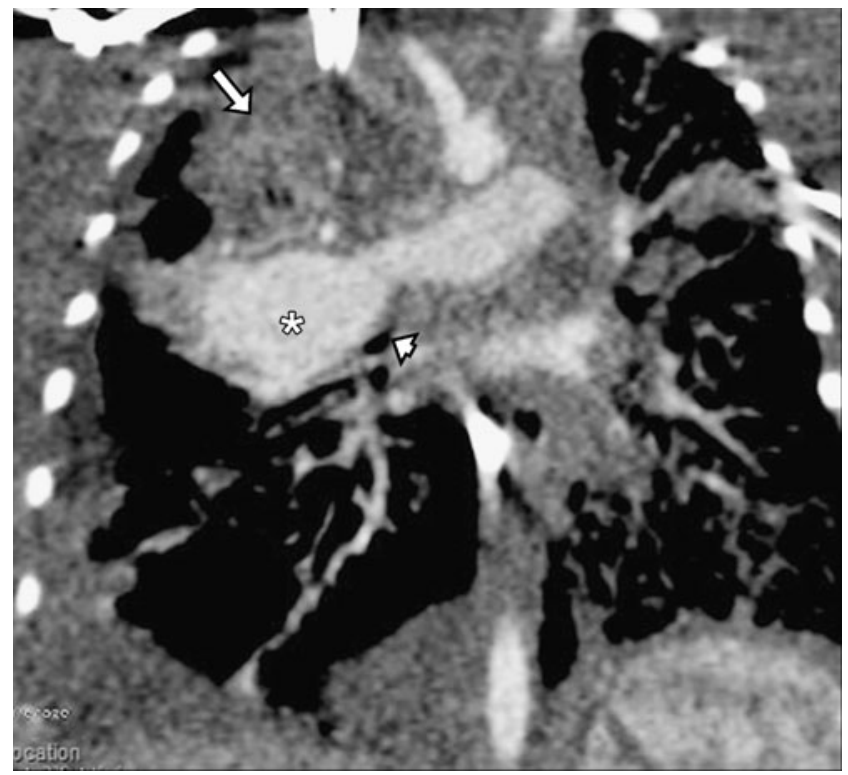

Fig. 2 Contrast-enhanced CT of the chest

pulmonary insufficiency and aneurysmal dilatation of the pulmonary arteries. Infants might present with mild respiratory symptoms or with significant respiratory compromise requiring early surgical repair [1]. Severe respiratory compromise is caused by tracheobronchomalacia and compression of the large airways by the dilated pulmonary arteries, with resultant air-trapping and further atelectasis. $\mathrm{CT}$ is helpful to delineate pulmonary arterial and airway anatomy and is also useful on postsurgical evaluation [2].

\section{References}

1. Kirshbom PM, Kogon BE (2004) Tetralogy of Fallot with absent pulmonary valve syndrome. Semin Thorac Cardiovas Surg Pediatr Card Surg Annu 7:65-71

2. Dillman J, Hernandez R (2009) Role of CT in the evaluation of congenital cardiovascular disease in children. AJR 192:1219-1231 